\title{
Fabrication of Impedance Sensor with Hydrophilic Property to Monitor Soil Water Content for Slope Failure Prognostics
}

\author{
Masato Futagawa, ${ }^{1,2 *}$ Tatsumi Ito, ${ }^{1}$ Shin Ogasahara, ${ }^{1}$ \\ Kenichiro Kusano, ${ }^{3}$ Yasushi Fuwa, ${ }^{4}$ and Mitsuru Komatsu ${ }^{5}$ \\ ${ }^{1}$ Department of Electrical and Electronic Engineering, Shizuoka University, \\ 3-5-1 Johoku, Naka-ku, Hamamatsu, Shizuoka 432-8561, Japan \\ ${ }^{2}$ Graduate School of Science and Technology, Research Division, Shizuoka University, \\ 3-5-1 Johoku, Naka-ku, Hamamatsu, Shizuoka 432-8561, Japan \\ ${ }^{3}$ Device Integration Division, LAPIS Semiconductor Co., Ltd. Miyagi Plant, \\ 1 Okinodaira, Ohira-mura, Kurokawa-gun, Miyagi 981-3693, Japan \\ ${ }^{4}$ Faculty of Engineering, Shinshu University, \\ 4-17-1 Wakasato, Nagano City, Nagano 380-8553, Japan \\ ${ }^{5}$ Integrated Intelligence Center, Okayama University, \\ 3-1-1 Tsushimanaka, Okayama City, Okayama 700-8530, Japan
}

(Received November 1, 2020; accepted February 19, 2021; online published March 4, 2021)

Keywords: soil water content, impedance sensor, LSI technology, hydrophilic property, slope failure prognostics

To minimize the damage caused by slope failure, knowledge of the increase in water content in mountain soil is important. Our group has been studying miniaturized impedance sensors for multipoint measurements in soil. Conventional sensors with a $\mathrm{SiN}_{x}$ top film sometimes cannot detect changes in the water content in soil resulting from rain. Experiments on the slide distances of water droplets were performed using $\mathrm{SiO}_{x}$ and $\mathrm{SiN}_{x}$ films. As the slide distance of the $\mathrm{SiO}_{x}$ film was shorter than that of the $\mathrm{SiN}_{x}$ film, it was confirmed that the $\mathrm{SiO}_{x}$ film is more hydrophilic than the $\mathrm{SiN}_{x}$ film. To improve contact characteristics between the sensor surface and free water in soil, we covered our conventional sensor chip with a hydrophilic $\mathrm{SiO}_{x}$ film. As a contact property test, the sensor chip measured the impedances of model soils. The proposed sensor achieved stable contact with the free water in the soil. Moreover, the chip operated for a long period of time on a mountain slope. The sensor could measure nearly theoretical outputs in response to rainfall. Thus, we succeeded in fabricating a stable soil monitor sensor with a hydrophilic $\mathrm{SiO}_{x}$ film.

\section{Introduction}

Natural disasters due to rainfall-induced slope failure and soil fall happen all over the world. Peoples' lives and their houses suffer serious damage in the disasters. ${ }^{(1)}$ Wired sensors, tilt sensors, ${ }^{(2)}$ and GPS sensors, which can detect the start of soil sliding, are useful for facilitating

*Corresponding author: e-mail: futagawa.masato@shizuoka.ac.jp

https://doi.org/10.18494/SAM.2021.3155 
the announcement of an evacuation signal just before the slope fails. When the degree of hazard can be detected well before a slope failure, evacuees have enough time to evacuate. Therefore, a prognostic of slope failure is needed. On the other hand, some groups have been studying the monitoring of water content in soil. ${ }^{(3-5)}$ When the water content in soil is increased, the soil frictional force is decreased and the soil weight is increased. Measurement of the water content can thus be used to evaluate the danger level of slope failure.

Water content sensors have several types of devices: a tensiometer ${ }^{(6-8)}$ to measure the suction force, and electrical impedance sensors, which are mainly of the capacitance measurement type, ${ }^{(9-11)}$ time domain reflectometry (TDR) type, ${ }^{(12-16)}$ or electrical conductivity type. ${ }^{(17,18)}$ Sensors for electrical impedance measurements of soil are generally superior in terms of longevity and they lack the need for periodic maintenance. Our group has been studying miniaturized impedance sensors fabricated by Si LSI technology ${ }^{(18,19)}$ for the measurement of soil water content. Additionally, we have been conducting research on slope failure prognostics using water content sensors. An electrical-conductivity-type sensor with low-power and lowfrequency operation succeeded in monitoring the changes in water content in soil on a mountain slope, corresponding to the amount of rainfall. ${ }^{(20)}$ Before installing the sensor on the mountain, its measurement sensitivity was confirmed using model soil with several different water contents in our laboratory. In this experiment, it was also confirmed that each water content was detected correctly. Therefore, the sensor was installed on the slope of the mountain. However, sometimes the sensor failed to respond to rainfall, as shown in Fig. 1. In order to achieve stable measurements, it was imperative to determine the cause of the problem and devise solutions. In this study, we confirmed that the use of $\mathrm{SiN}_{x}$ and $\mathrm{SiO}_{x}$ films, which have the property of water retention, can serve as a solution. After experiments, a new sensor chip with a $\mathrm{SiO}_{x}$ film to solve the problem of measurement failure was fabricated. The new sensor chip and conventional sensor chip measured model soils with different water contents to verify their effectiveness. Finally, on-site and continuous measurements using the chips embedded in a mountain slope were performed.

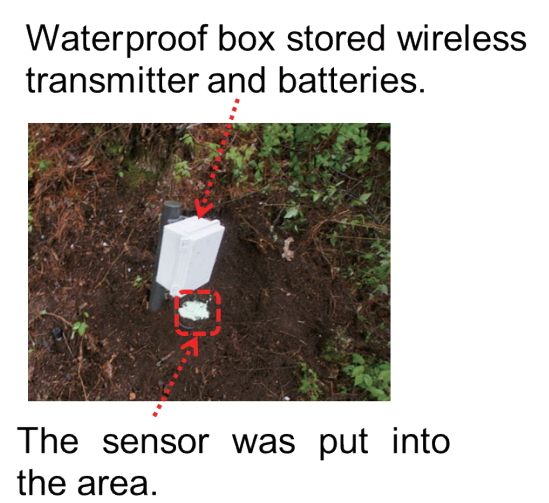

(a)

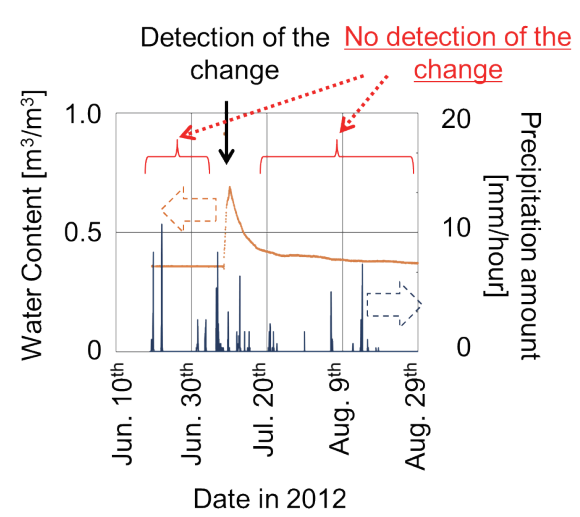

(b)

Fig. 1. (Color online) Photograph of previous sensor and measurement results of the sensor. The sensor monitored the soil on the slope of a mountain but sometimes failed to measure changes in water content. (a) Photograph of the sensor system. (b) Measurement results of the sensor. 


\section{Examining Cause of Measurement Problem and Proposed Solutions}

Figure 1 shows a photograph of the previous sensor system ${ }^{(20)}$ and measurement results of the sensor. The conventional sensor sometimes could not detect changes in the water content in the soil when it rained. We speculated on the causes of this and proposed solutions.

\subsection{Conventional sensor chip and failure mechanism}

To understand the cause of nondetection, the measurement setup and a cross-sectional view of the measurement space are shown in Fig. 2. The measurement current flowed in the space above the sensor surface between the Pt electrodes. The height of the measurement range is approximately $5 \mathrm{~mm}$ from the surface because the distance between the Pt electrodes is $2.27 \mathrm{~mm}$. The surface material of the space between the Pt electrodes is a $\mathrm{SiN}_{x}$ film. As the soil particles are hydrophilic, it is estimated that free water does not reach the sensor surface when the sensor surface is more hydrophobic than the soil, as shown in Fig. 3(a). In this situation, there are air pockets on the sensor surface. Therefore, conventional sensors sometimes cannot

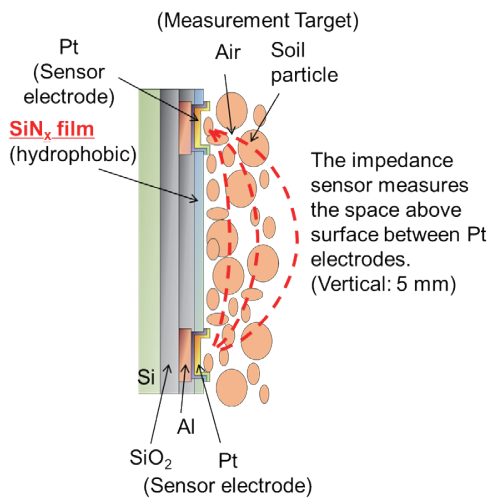

Fig. 2. (Color online) Image of impedance measurement in soil. Our previous sensor chip measured the space between the Pt electrodes of the sensor chip. One Pt electrode applied voltage and the other Pt electrode measured current.

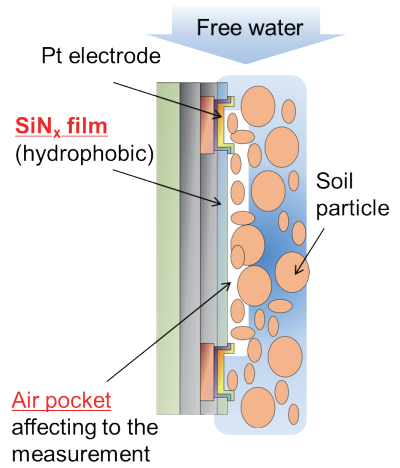

(a)

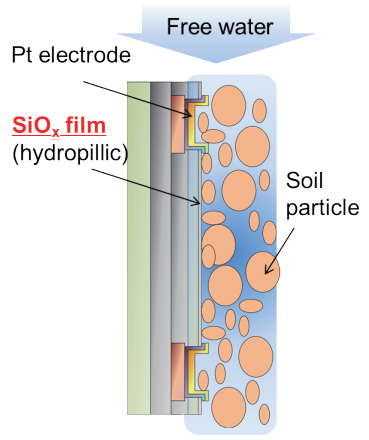

(b)

Fig. 3. (Color online) Images of the flowing water on sensor surfaces. (a) Hydrophobic surface on previous sensor chip. (b) Hydrophilic surface on proposed sensor chip. 
detect changes in water content. To solve this problem, we proposed a new sensor chip in which a $\mathrm{SiO}_{x}$ film is added on the $\mathrm{SiN}_{x}$ film as shown in Fig. 3(b). When the $\mathrm{SiO}_{x}$ film is almost as hydrophilic as the soil, the sensor can measure changes in water content.

\subsection{Comparing the hydrophilicity of $\mathrm{SiN}_{x}$ and $\mathrm{SiO}_{x}$ films}

The test chips with $\mathrm{SiN}_{x}$ and $\mathrm{SiO}_{x}$ films were fabricated on $\mathrm{SiO}_{2} / \mathrm{Si}$ substrates. The films were made by the plasma CVD method. To confirm the hydrophilic properties, we added $10 \mu \mathrm{L}$ of the water dropwise on the test chips, which were tilted at an angle of $50^{\circ}$ from the horizontal, as shown in Fig. 4(a). Then, the slide distances of the chips were compared. We confirmed that we could visually capture the ability of free water to be retained on the surface of the chip. Figure 4(b) shows the water drops $10 \mathrm{~s}$ after adding the water. The slide distance of the $\mathrm{SiO}_{x}$ film was shorter than that of the $\mathrm{SiN}_{x}$ film. These results suggest that the $\mathrm{SiO}_{x}$ film is more hydrophilic than the $\mathrm{SiN}_{x}$ film. Therefore, we propose a new sensor chip with a $\mathrm{SiO}_{x}$ film added on top of the $\mathrm{SiN}_{x}$ film of the previous sensor chip.

\section{Fabrication of New Sensor Chip}

The new sensor chip was fabricated by Si LSI technology and is shown in Fig. 5. Figure 5(a) shows a photograph of the new sensor chip. The size of the chip is $5 \times 5 \mathrm{~mm}^{2}$. Pt electrodes

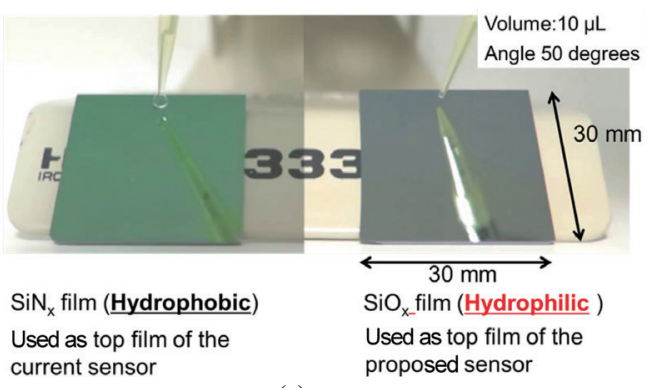

(a)

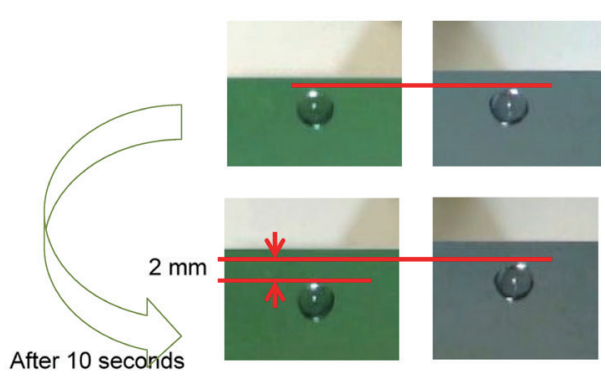

(b)

Fig. 4. (Color online) Experiments on adding water drops for comparison between hydrophobic and hydrophilic materials. (a) Photographs of the experimental setup. (b) Water flow distances of hydrophobic and hydrophilic wafers.

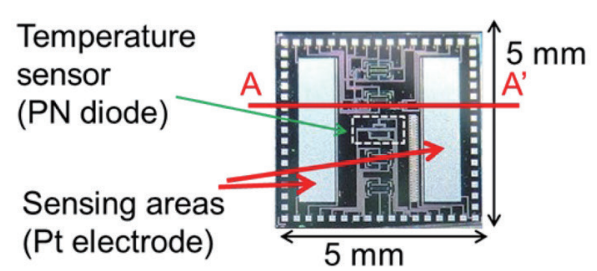

(a)

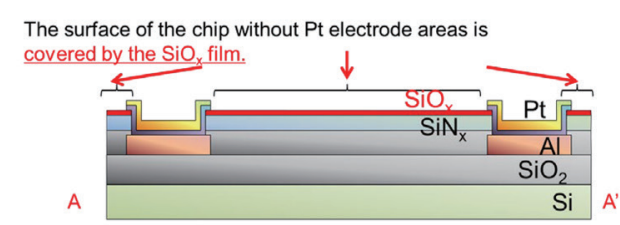

(b)

Fig. 5. (Color online) Proposed sensor chip fabricated by LSI process. (a) Photograph of the sensor chip. (b) Cross-sectional view along line $\mathrm{A}-\mathrm{A}^{\prime}$ in (a). 
for impedance measurement and a PN junction diode for a temperature sensor were integrated into the chip. Figure 5(b) shows a cross-sectional view of the chip. The thickness of the top film of $\mathrm{SiO}_{x}$ placed on the $\mathrm{SiN}_{x}$ film is $200 \mathrm{~nm}$. When there was no $\mathrm{SiN}_{x}$ under the $\mathrm{SiO}_{x}$, the Al electrode corroded and electric leakage occurred, so the $\mathrm{SiN}_{x}$ film was not removed from the new chip. The thickness of the Pt electrodes, to which voltage and current were applied for the impedance measurement, was $100 \mathrm{~nm}$.

\section{Experiments}

\subsection{Model soil experiment}

When an air pocket exists on the sensor surface, the measured impedance becomes larger than the measurement results under a stable contact condition without the air pocket. In our experiment, the $\mathrm{SiN}_{x}$ sensor of a conventional sensor and the $\mathrm{SiO}_{x}$ sensor of the proposed sensor were used to measure the model granite soil, as shown in Fig. 6. A photograph of the model soil experiment is shown in Fig. 6(a). To make the water content of the soil uniform, the soil was mixed and packed in the container to the same density. The water mixed with the model soils was made by mixing $\mathrm{NaCl}$ with pure water. The ion concentrations of the water were 0.16 , 10 , and $100 \mathrm{mS} / \mathrm{m}$. By using the water with the three concentrations, model soils with three different water contents, $0.15,0.3$, and $0.45 \mathrm{~m}^{3} / \mathrm{m}^{3}$, were prepared. The impedances of the model soils were measured using the previous and proposed sensors with the measurement circuit shown in Fig. 6(b). The impedance $Z$ of the soil was calculated by dividing the voltage $V_{\text {Sens }}$ by the current $I_{R}$ as shown in Fig. 6(b). The measurement results of the $\mathrm{SiN}_{x}$ and $\mathrm{SiO}_{x}$ sensors were compared. Figure 7 shows the ratio of the impedance measurement results using model soils with water contents of $0.15,0.3$, and $0.45 \mathrm{~m}^{3} / \mathrm{m}^{3}$ and ion concentrations of $0.16,10$, and $100 \mathrm{mS} / \mathrm{m}$ in the water. The graph shows the ratio of impedances measured by the $\mathrm{SiN}_{x}$ sensor and the $\mathrm{SiO}_{x}$ sensor. When the ratio was one, the measured impedances of the two sensors were equal. When an air pocket existed above the $\mathrm{SiN}_{x}$ sensor surface, the ratio was larger than one. These results show that the ratio increased with the water content. This finding suggests that the $\mathrm{SiO}_{x}$ chip is more capable of stable measurements owing to its better contact with free water.

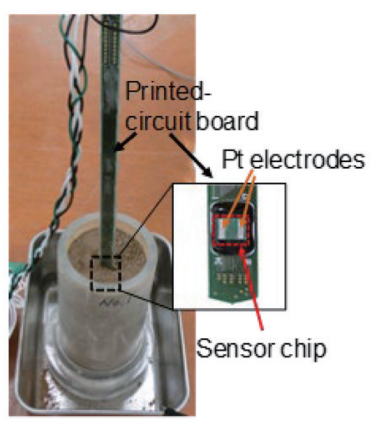

(a)

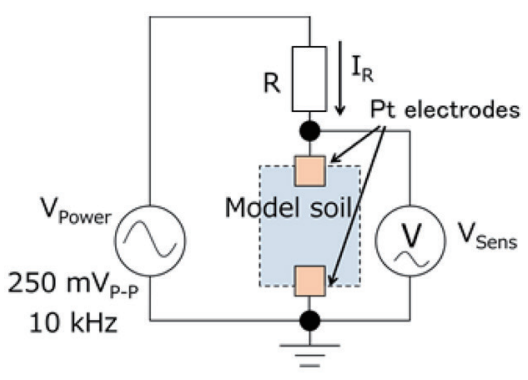

(b)

Fig. 6. (Color online) Experimental setup to measure impedance in model soil. (a) Photograph of impedance measurement in model soil. (b) Measurement circuit to measure model soil using the sensors. 


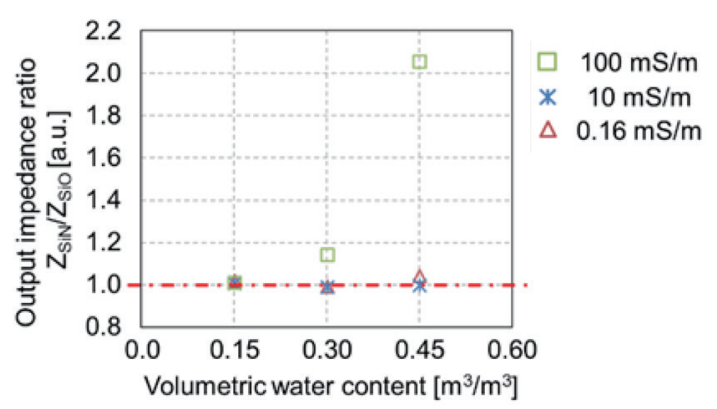

Fig. 7. (Color online) Results of stability test in which impedances were measured with the $\mathrm{SiO}_{x}$ sensor and the $\mathrm{SiN}_{x}$ sensor.

\subsection{On-site and long-term measurement on slope of mountain}

For on-site and continuous monitoring on a mountain slope, a wireless sensor system was fabricated, as shown in Fig. 8. As shown in Fig. 8(a), a hole was dug in the slope of the mountain, into which a sensor was inserted. The $\mathrm{SiO}_{x}$ and $\mathrm{SiN}_{x}$ sensors were inserted into separate holes. The sensor control circuit applied a voltage and measured the current of the Pt electrodes of the sensors. The circuits also converted the signal from analog to digital. The circuits were covered by a plastic tube for waterproofing and were buried in the soil. Figure 8(b) shows the area where the sensors were inserted and the waterproof box used to store the wireless transmitter and batteries. The wireless transmitter ${ }^{(21,22)}$ used a radio frequency of $429 \mathrm{MHz}$ because the influence of trees on a $429 \mathrm{MHz}$ radio signal is smaller than that if a higher radio frequency is used. ${ }^{(23)}$

The $\mathrm{SiO}_{x}$ and $\mathrm{SiN}_{x}$ sensors performed measurements for around five months. Figure 9 shows the conductivity, the reciprocal of impedance, of the two sensors plotted over the five months. When the water content in the soil became large, the conductivity signal also became large. The changes in the $\mathrm{SiN}_{x}$ sensor signal were small when it rained, as shown in Fig. 9(a). In contrast, the changes in the $\mathrm{SiO}_{x}$ sensor signal were large, as shown in Fig. 9(b). The measurement results in Fig. 9(b) were converted into volumetric water content information using the calibration curve, as shown in Fig. 10. The graph was obtained by using model soils with uniform water content. ${ }^{(20)}$

The approximate curve is represented by Eq. (1). The coefficient of determination $R^{2}$ of the curve is 0.9441 , indicating satisfactory measurement accuracy.

$$
W C=0.1989\left\{\log _{10}(E C)\right\}^{3}+1.8365\left\{\log _{10}(E C)\right\}^{2}+5.7115 \log _{10}(E C)+6.3054
$$

Here, $W C$ is volumetric water content and $E C$ is electric conductivity. The converted results are shown in Fig. 11. We confirmed that the water content values were consistent with the expected values. These results confirm that the $\mathrm{SiO}_{x}$ sensor can measure changes in the soil water content resulting from precipitation. 


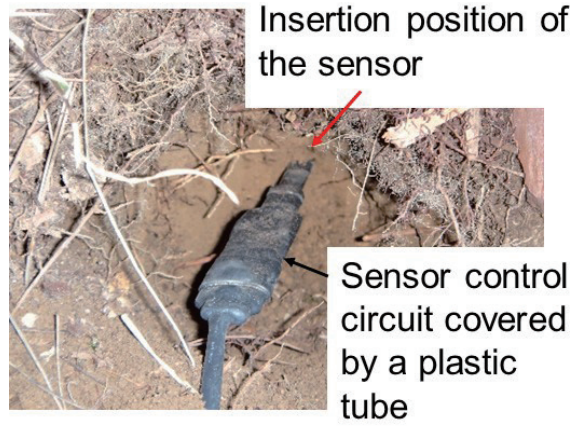

(a)

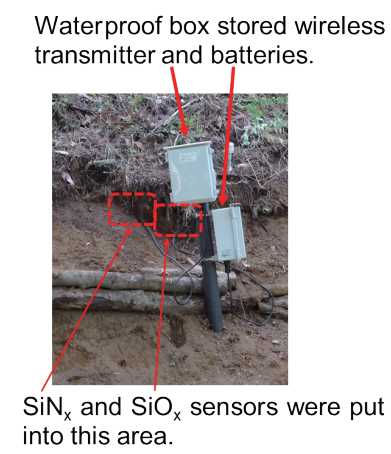

(b)

Fig. 8. (Color online) Photographs of the sensor system for continuous monitoring of a mountain slope. (a) Sensor chip and sensor control circuit board buried in soil on slope of mountain. (b) Setup of sensor system with wireless transmitter and batteries.

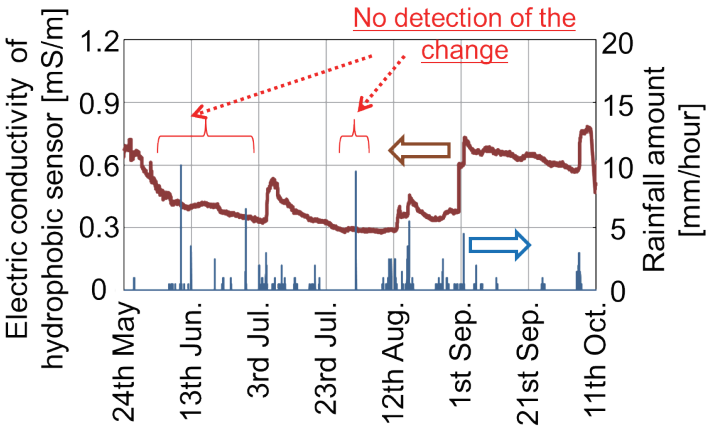

(a)

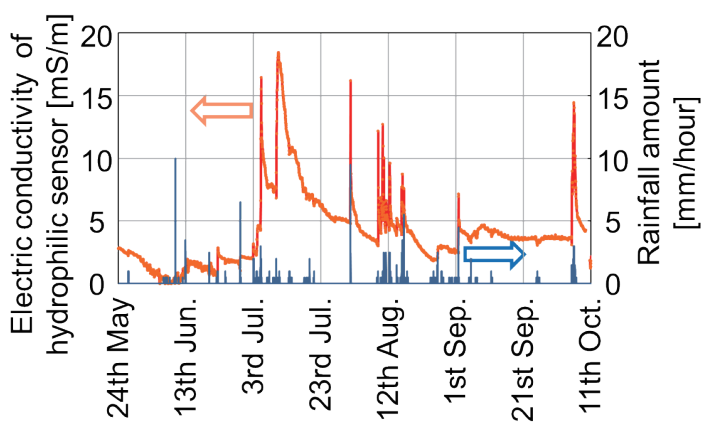

(b)

Fig. 9. (Color online) Measurement results of the sensors and rainfall amount. The upper arrows indicate the conductivity, whereas the lower arrows indicate the rainfall amount. (a) Conventional $\mathrm{SiN}_{x}$ sensor. (b) Proposed $\mathrm{SiO}_{x}$ sensor.

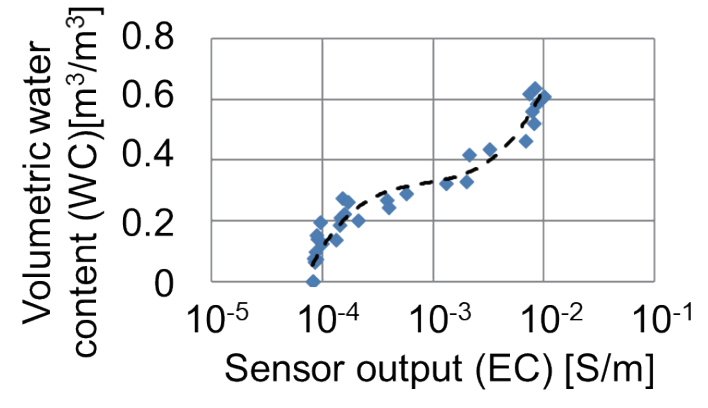

Fig. 10. (Color online) Calibration curve of $W C$ and $E C$ using model soil. The points are the measurement data of the model soil and the broken line is the approximate curve.

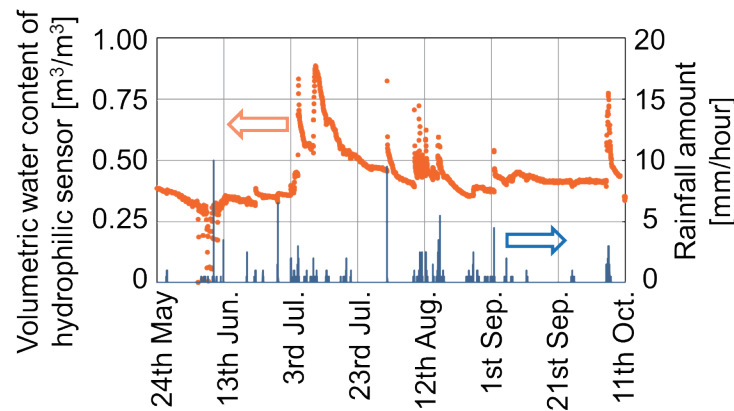

Fig. 11. (Color online) Results of Fig. 9. converted to $W C$ values. 


\section{Conclusions}

Our group has been studying miniaturized impedance sensors to minimize the damage caused by slope failure. Our conventional sensor with a $\mathrm{SiN}_{x}$ top film sometimes failed to detect changes in the water content in soil resulting from rain. It was speculated that the problem was due to the fact that the $\mathrm{SiN}_{x}$ film was more hydrophobic than the soil. Experiments on the slide distances of water droplets were performed using $\mathrm{SiO}_{x}$ and $\mathrm{SiN}_{x}$ films. Because the slide distance of the $\mathrm{SiO}_{x}$ film was shorter than that of the $\mathrm{SiN}_{x}$ film, we confirmed that the $\mathrm{SiO}_{x}$ film was more hydrophilic than the $\mathrm{SiN}_{x}$ film. To improve the contact characteristics between the sensor surface and free water in soil, a new sensor chip was fabricated with a $\mathrm{SiO}_{x}$ film in the space between the Pt electrodes of the conventional sensor chip using LSI technology. To confirm the contact condition between free water and the sensor surface, impedance measurements were performed in model soils using the conventional $\mathrm{SiN}_{x}$ and proposed $\mathrm{SiO}_{x}$ sensors. We confirmed that the impedance using the $\mathrm{SiO}_{x}$ sensor was smaller than that using the $\mathrm{SiN}_{x}$ sensor. The results showed that the contact condition of the $\mathrm{SiO}_{x}$ sensor was better than that of the $\mathrm{SiN}_{x}$ sensor. On-site and long-term measurements on a mountain slope were performed using these sensors for five months. The changes in the $\operatorname{SiN}_{x}$ sensor signal were small when it rained, whereas the changes in the $\mathrm{SiO}_{x}$ sensor signal were large. The water content values obtained using the $\mathrm{SiO}_{x}$ sensor conformed to the expected results. Thus, we succeeded in fabricating a stable soil monitor sensor by using a hydrophilic $\mathrm{SiO}_{x}$ film.

\section{Acknowledgments}

This work was partially supported by Grants-in-Aid for Young Scientists (B) (Numbers 24760277 and 17K17785) from the Japan Society for the Promotion of Science (JSPS), and Fiscal 2014 Sekisui Chemical Grants for Research on Manufacturing Based on Innovations Inspired by Nature.

\section{References}

1 R. C. Wilson and D. K. Keefer: Bull. Seismol. Soc. Am. 73 (1983) 863.

2 T. Uchimura, I. Towhata, T. T. L. Anh, J. Fukuda, C. J. B. Bautista, L. Wand, I. Seko, T. Uchida, A. Matsuoka, Y. Ito, Y. Onda, S. Iwagami, M. Kim, and N. Sakai: Landslides 7 (2010) 351. https://doi.org/10.1007/s10346-009$\underline{0178-\mathrm{Z}}$

3 A. Tohari, M. Nishigaki, and M. Komatsu: J. Geotech. Geoenviron. Eng. 133 (2007) 575. https://doi. org/10.1061/(ASCE)1090-0241(2007)133:5(575)

4 S. J. Harris, R. P. Orense, and K. Itoh: Landslides 9 (2012) 349. https://doi.org/10.1007/s10346-011-0309-1

5 R. P. Orense, S. Shimoma, K. Maeda, and I. Towhata: J. Nat. Disaster Sci. 26 (2004) 15. https://doi. org/10.2328/jnds.26.15

6 L. A. Richards: Soil Sci. 53 (1942) 241.

7 A. Klute and W. R. Garder: Soil Sci. 93 (1962) 204.

8 K. Lunkenheimer and K.-D. Wantke: Colloid Polym. Sci. 259 (1981) 354. https://doi.org/10.1007/BF01524716

9 H. Eller and A. Denoth: J. Hydrol. 185 (1996) 137. https://doi.org/10.1016/0022-1694(95)03003-4

10 D. A. Robinson, T. J. Kelleners, J. D. Cooper, C. M. K. Gardner, P. Wilson, I. Lebron, and S. Logsdon: Vadose Zone J. 4 (2005) 992. https://doi.org/10.2136/vzj2004.0131

11 L. Chow, Z. Xing, H. W. Rees, F. Meng, J. Monteith, and L. Stevens: Sensors 9 (2009) 9398. https://doi. org/10.3390/s91109398 
12 F. N. Dalton and M. Th. Van Genuchten: Geoderma 38 (1986) 237. https://doi.org/10.1016/0016-7061(86)90018$\underline{2}$

13 A. Alharthi and J. Lange: Water Resour. Res. 23 (1987) 591. https://doi.org/10.1029/WR023i004p00591

14 K. Noborio: Comput. Electron. Agric. 31 (2001) 213. https://doi.org/10.1016/S0168-1699(00)00184-8

15 J. P. Walker, G. R. Willgoose, and J. D. Kalma: J. Hydrol. 293 (2004) 85. https://doi.org/10.1016/ j.jhydrol.2004.01.008

16 S. Yurui, P. S. Lammers, M. Daokun, L. Jianhui, and Z. Qingmeng: Sens. Actuators, A 147 (2008) 352. https:// doi.org/10.1016/j.sna.2008.05.014

17 T. Saito, H. Fujimaki, and M. Inoue: Am. J. Env. Sci. 4 (2008) 683. https://thescipub.com/abstract/10.3844/ ajessp.2008.683.692

18 M. Futagawa, T. Iwasaki, T. Noda, H. Takao, M. Ishida, and K. Sawada: Jpn. J. Appl. Phys. 48 (2009) 04C1841. https://doi.org/10.1143/JJAP.48.04C184

19 M. Futagawa, T. Iwasaki, H. Murata, M. Ishida, and K. Sawada: Sensors 12 (2012) 8338. https://doi. org/10.3390/s120608338

20 M. Futagawa, M. Komatsu, H. Suzuki, Y. Takeshita, Y Fuwa, and K. Sawada: IEEJ Trans. Sens. Micromach. 133 (2013) 278 (in Japanese). https://doi.org/10.1541/ieejsmas.133.278

21 H. Nose, M. Bao, K. Mizuta, Y. Yoshikawa, H. Kunimune, M. Niimura, and Y. Fuwa: IEICE Trans. Fundam. Electron. Commun. Comput. Sci. E93-A (2010) 1735.

22 D. Asano, D. Kuroyanagi, H. Suzuki, E. Motoyama, and Y. Fuwa: IEICE Trans. Commun. E97-B (2014) 1449.

23 H. Suzuki, Y. Fuwa, K. Yuki, D. K. Asano, M. Komatsu, Y. Takeshita, K. Sawada, M. Futagawa, and H. Nose: Int. Technical Conf. Circuits/Systems, Computers and Communications 2014 (ITC-CSCC 2014).

\section{About the Authors}

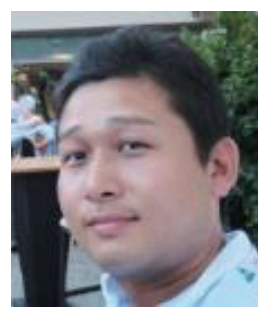

Masato Futagawa received his B.A. and M.S. degrees in electrical and electronic engineering and his $\mathrm{Ph} . \mathrm{D}$. in electronic and information engineering, all from Toyohashi University of Technology, Aichi, Japan, in 2000, 2002, and 2011, respectively. From 2002 to 2007, he worked at Toshiba Co. From 2008 to 2014, he was at Toyohashi University of Technology. He is currently an associate professor at Shizuoka University, Japan. His current research interests focus on multimodal sensors integrated with $\mathrm{pH}$, ion concentration, water content, and reduction-oxidation (redox) sensors in the biosensor, environmental, and agricultural fields. He is a member of IEEJ, JSAP, and IEEE. (futagawa.masato@shizuoka.ac.jp)

Tatsumi Ito received his B.A. degree in electrical and electronic engineering from Shizuoka University, Shizuoka, Japan, in 2017.

Shin Ogasahara received his B.A. degree in electrical and electronic engineering from Shizuoka University, Shizuoka, Japan, in 2016.

Kenichiro Kusano received his B.A. and M.S. degrees in electronic engineering from Fukuoka University, Fukuoka, Japan, in 1994 and 1996, respectively. He then joined Oki Electric Industry Co., Ltd. He currently works at LAPIS Semiconductor Co., Ltd. 


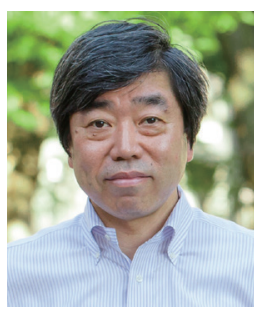

Yasushi Fuwa received his B.E. and M.E. degrees from Shinshu University in 1981 and 1983, respectively. From 1983 to 1992, he was a research associate in the Faculty of Engineering, Shinshu University. He received his Ph.D. degree from Nagoya Institute of Technology in 1992. He is now a professor in the Graduate School of Science and Technology, Shinshu University. His current research areas include ad-hoc networks, sensor networks, computer networks, and e-learning. He is a member of JSiSE, IEICE, IPSJ, and IEEE.

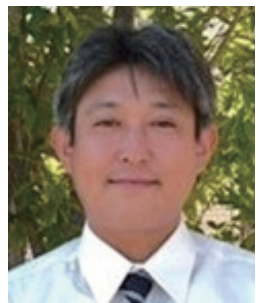

Mitsuru Komatsu was born in Kumamoto, Japan, in 1972. He received his B.A. and M.S. degrees and his Ph.D. degree in civil engineering, all from Okayama University, Okayama, Japan, in 1995, 1997, and 2000, respectively. $\mathrm{He}$ is currently an associate professor with Okayama University. His current research interests focus on methods of measuring hydraulic properties in unsaturated soil. 